\title{
HUBUNGAN POLA ASUH ORANG TUA DENGAN PERILAKU SEKSUAL REMAJA DI SMK TEKNOLOGI MIGAS PEKANBARU
}

\author{
Lora Marlita1, Putri Wulandini S², Yusmaharni,Erika Siswaty Zega3 \\ 12Program Studi D III Keperawatan \\ Email lora.marlita@univrab.ac.id
}

\begin{abstract}
Sexual behavior is something that is considered to affect the behavior of self-esteem, parent-child relationships, the tendency to seek sexual sensation, the existence of a deviant peer, and the use of pornographic media. Sexual behavior also occurs, because of the physical changes that occur because of the active sex hormones in the body of a very large influence in the cause of sexual urges. Pattern of parenting is the pattern of interaction between the child and the parents include the fulfillment of physical needs, and socialization of prevailing norms in the community so that children can live in harmony with their environment. The general purpose of Scientific Writing is To know how the relationship of parental parenting with sexual behavior in adolescents in SMK Tecnology Oil And Gas Pekanbaru, descriptive correlation research design. The research was conducted on June, 2018, the sample in this study were the students in SMK Tecnology Oil And Gas Pekanbaru amounted to 112 people. Research technique area (cluster) sampling. Chi-Square statistical test results obtained $p$ value $=0.204>0.05$, it can be concluded there is no relationship Parenting Parenting With Sexual Behavior In Teenagers In SMK Tecnology Oil And Gas Pekanbaru 2018. Teenagers in SMK Tecnology Oil And Gas Pekanbaru, is expected to direct the association in a positive direction so that the tendency to engage in sexual behavior can be avoided such as following extracurricular activities, religious activities, youth, etc. in accordance with the interests of student talent.
\end{abstract}

Keywords $\quad$ : Patterns of Custody, Sexual Behavior

\begin{abstract}
ABSTRAK
Perilaku seksual merupakan sesuatu yang dianggap mepengaruhi perilaku harga diri, hubungan orang tua-anak, kecenderungan mencari sensasi seksual, keberadaan teman sebaya yang menyimpang, dan penggunaan media pornografi. Perilaku seksual juga terjadi, karena perubahan fisik yang terjadi karena mulai aktifnya hormon seks dalam tubuh yang sangat besar pengaruhnya dalam menimbulkan dorongan seksual. Pola asuh adalah pola interaksi antara anak dengan orang tua meliputi pemenuhan kebutuhan fisik, serta sosialisasi norma-norma yang berlaku dimasyarakat agar anak dapat hidup selaras dengan lingkungannya. Tujuan umum penelitian ini adalah Untuk mengetahui bagaimana hubungan pola asuh orangtua dengan perilaku seksual pada remaja di SMK Teknologi Migas Pekanbaru, desain penelitian deskriptif korelasi. Penelitian ini dilaksanakan pada bulan Juni 2018, sampel dalam penelitian ini adalah siswa-siswi di SMK Teknologi Migas Pekanbaru berjumlah 112 orang. Teknik penelitian area (cluster) sampling. Hasil uji statistik Chi-Square diperoleh nilai $\mathrm{p}=0.204>0.05$, maka dapat disimpulkan tidak ada hubungan Pola Asuh Orangtua Dengan Perilaku Seksual Pada Remaja Di SMK Teknologi Migas Pekanbaru Tahun 2018. Remaja di SMK Teknologi Migas Pekanbaru, diharapkan lebih mengarahkan pergaulannya ke arah yang positif sehingga kecendrungan untuk melakukan perilaku seksual dapat dihindari seperti mengikuti kegiatan ekstrakurikuler, kegiatan keagamaan, karang taruna, dan sebagainya sesuai dengan minat bakat siswa.
\end{abstract}

Kata Kunci : Pola Asuh, Perilaku Seksual 


\section{PENDAHULUAN}

Masa remaja merupakan masa transisi dari masa anak kemasa dewasa (Santrock, 2007). Sofyan (2013) mengatakan remaja adalah suatu tahap kehidupan yang bersifat peralihan. Badan Kesehatan Dunia (WHO) menyebutkan, seperlima dari penduduk di dunia adalah remaja, dengan 900 juta penduduk remaja berada di negara yang sedang berkembang dengan 20 persennya berada di Indonesia. Pada masa tersebut keadaan fisik seorang remaja mengalami pertumbuhan dan perkembangan yang sangat pesat. Diantara perubahan-perubahan fisik itu yang terbesar pengaruhnya pada perkembangan remaja adalah tubuh yaitu mulai berfungsinya alat-alat reproduksi dan tanda-tanda seksual sekunder yang tumbuh Perilaku seksual merupakan sesuatu yang dianggap mepengaruhi perilaku harga diri, hubungan orang tua-anak, kecenderungan mencari sensasi seksual, keberadaan teman sebaya yang menyimpang, dan penggunaan media pornografi. Perilaku seksual juga terjadi, karena perubahan fisik yang terjadi karena mulai aktifnya hormon seks dalam tubuh yang sangat besar pengaruhnya dalam menimbulkan dorongan seksual. Pada saat ini, pacaran di dalam kalangan remaja merupakan sesuatu hal yang tidak asing lagi. Hampir sebagian kalangan remaja siswasiswi pernah berpacaran. Hasil penelitian Ine' fronteira (2009) diempat negara Eropa pada tahun 2005 sampai 2006 terhadap 1557 responden, ditemukan bahwa lebih dari tiga perempat responden telah mempunyai pacar dan setengah dari jumlah tersebut melakukan hubungan heteroseksual.

Di Indonesia kasus perilaku seksual pada remaja terjadi peningkatan setiap tahunnya. Riset yang dilakukan Komisi Perlindungan Anak Indonesia (KPAI) pada tahun 2015 ditemukan sebanyak $97 \%$ remaja pernah menonton film porno dan 93,75 pernah melakukan adegan intim bahkan hingga melakukan sex oral. Pada tahun 2013 KPAI juga melakukan survei tentang perilaku seksual remaja didapatkan hasil sebanyak $32 \%$ remaja usia 14 hingga 18 tahun di kota besar di Indonesia (Jakarta, Surabaya, dan Bandung) pernah berhubungan seksual pranikah. Fenomena diatas menunjukkan bahwa remaja di Indonesia lebih banyak terjerumus kepada perilaku seksual.

Pola asuh merupakan suatu proses mendidik, membimbing, dan mendisiplinkan serta melindungi anak untuk mencapai kedewasaan sesuai dengan norma dalam masyarakat. Pola asuh orang tua sangat mempengaruhi bagaimana anak berperilaku dan bentuk kepribadian anak secara keseluruhan. Tipe pola asuh orang tua terbagi atas tiga tipe yaitu : pola asuh demokratis, pola asuh otoriter, dan pola asuh permisif. Masing-masing pola asuh tersebut mempunyai dampak bagi perkembangan anak dan remaja (Santrock, 2007).

Penerapan pola asuh untuk setiap orang tua dapat berbeda-beda. Menurut Baumrind (1971 dalam Santrock, 2007) dalam kehidupan sehari-hari kebanyakan orang tua menggunakan kombinasi dari kesemua pola asuh yang ada, akan tetapi satu jenis pola asuh akan terlihat lebih dominan daripada pola asuh lainnya dan sifatnya hampir stabil sepanjang waktu.

Hasil penelitian Stadler (2010) menunjukkan ada hubungan antara pola asuh orang tua dengan masalah perilaku seksual pada anak remaja di negara Jerman seperti masalah hubungan dengan teman sebaya. Stadler mengatakan ada resiko tinggi terjadinya masalah perilaku seksual pada remaja usia 15-18 tahun jika dukungan dari orang tua mereka rendah terhadap perkembangannya. Penelitian Turner (2009) menunjukkan bahwa pola asuh demokratis terbukti dapat meningkatkan prestasi akademik pada mahasiswa dan penelitian Konnie (2013) menunjukkan mayoritas pola asuh orang tua di Italy adalah demokratis $(68,7 \%)$, diikuti dengan pola asuh otoriter 
$(16,7 \%)$ dan pola asuh permisif (14,6\%). Penelitian yang dilakukan oleh Nurmagupta (2014) di Yogyakarta menunjukkan mayoritas pola asuh orang tua adalah pola asuh permisif dan ada hubungan pola asuh dengan perilaku seksual beresiko di Kabupaten Bantul Yogyakarta.

Dari hasil survey yang dilakukan pada remaja di SMK teknologi migas pekanbaru, dari 8 orang remaja yang ditanyai 2 orang mengatakan memperoleh informasi tentang aktivitas seksual dari social media, 3 orang mengatakan senang mengumpul dengan teman sebaya karena mereka sering dimarahi oleh orang tua, dan 1 orang remaja mengatakan sering dimarahi oleh orang tuanya jika pulang terlamabat.

Berdasarkan uraian diatas maka peneliti ingin meneliti mengenai "Hubungan Pola Asuh Orangtua Dengan Perilaku Seksual Remaja Di SMK Teknologi Migas Pekanbaru Tahun 2018".

\section{METODE PENELITIAN}

Penelitian ini menggunakan jenis penelitian kuantitatif dengan desain deskriptif korelasi yaitu suatu studi yang mengkaji hubungan dua variabel atau lebih (Nursalam, 2011). Desai penelitian cross-sectional ini bertujuan untuk mengetahui hubungan antara variabel independen dengan variabel dependen. Pengumpulan data dilakukan sekaligus pada suatu saat,artinya tiap subjek penelitian hanya diobservasi sekali saja dan pengukuran dilakukan terhadap status karakter atau variabel pada saat pemeriksaan (Notoatmodjo, 2012). Penelitian ini bertujuan untuk mengetehui hubungan pola asuh orangtua dengan perilaku seksual remaja di SMK Teknologi Migas Pekanbaru. Populasi merupakan keseluruhan objek penelitian atau objek yang diteliti (Notoatmodjo, 2005). Populasi dalam penelitian ini adalah siswa kelas $\mathrm{XA}, \mathrm{XB}$, XIA, XIB, XIC, XIIA dan XIIB di SMK
Teknologi Migas Pekanbaru dengan jumlah 156 orang.

\section{HASIL DAN PEMBAHASAN}

1. Analisa Univariat

Tabel 4.1

Distribusi Frekuensi RespondenBerdasarkan Pola Asuh Orangtua di SMK Teknologi MigasPekanbaru 2018

\begin{tabular}{|c|c|c|}
\hline Pola Asuh & Frekuensi & Persentase \\
\hline Demokrasi & 106 & 94.6 \\
\hline Otoriter & 6 & 5.4 \\
\hline Permisif & 0 & 0 \\
\hline Total & 112 & 100 \\
\hline
\end{tabular}

Dari Tabel 4.1 dapat dilihat bahwa pola asuh orangtua di SMK Teknologi Migas Pekanbaru mayoritas demokratis yaitu sebanyak 106 responden (94.6\%).

Tabel 4.2

Distribusi Frekuensi RespondenBerdasarkan Perilaku Seksual Remaja di SMK Teknologi MigasPekanbaru 2018

\begin{tabular}{|l|c|c|}
\hline Perilaku Seksual & Frekuensi & Persentase \\
\hline Pernah & 16 & 14.3 \\
\hline Tidak pernah & 96 & 85.7 \\
\hline Total & 112 & 100 \\
\hline
\end{tabular}

Dari tabel 4.2 diatas dilihat bahwa perilaku seksual pada remaja di SMK Teknologi Migas Pekanbaru mayoritas tidak pernah yaitu sebanyak 96 responden $(85.7 \%)$ 
2. Analisa Bivariat

Tabel 4.3

Hubungan Pola Asuh Orangtua

Dengan Perilaku Seksual Pada

RemajaDi SMK Teknologi Migas

Pekanbaru Tahun 2018

\begin{tabular}{|l|l|l|l|l|}
\hline Pola asuh & \multicolumn{2}{|l|}{ Perilaku seksual } & N & \multirow{2}{*}{$\begin{array}{l}\text { p. } \\
\text { value }\end{array}$} \\
\cline { 2 - 4 } & Pernah & $\begin{array}{l}\text { Tidak } \\
\text { pernah }\end{array}$ & \\
\cline { 1 - 4 } Demokratis & 14 & 92 & 106 & \\
\cline { 2 - 4 } & $13.2 \%$ & $86.8 \%$ & 100 & \multirow{3}{*}{0.204} \\
\hline Otoriter & 2 & 4 & 6 & \\
\cline { 2 - 4 } & $33.3 \%$ & $66.7 \%$ & 100 & \\
& 16 & 96 & 112 & \\
& 14.3 & $85.7 \%$ & 199 & \\
\hline
\end{tabular}

\section{PEMBAHASAN}

Dari tabel 4.1 dapat dilihat bahwa pola asuh orangtua siswa-siswi di SMK Teknologi Migas Pekanbaru mayoritas demokratis yaitu sebanyak 106 responden (94.6\%). Dari pola asuh yang lebih tinggi adalah Pola Asuh Demokratis. Menurut asumsi peneliti pola asuh demokrasi dapat mengajarkan remaja untuk tidak melakukan perilaku seksual.

Pola asuh demokrasi berusaha mengarahkan anaknya secara rasional, berorientasi pada masalah yang dihadapi, menghargai komunikasi yang saling memberi dan menerima, menjelaskan alasan rasional yang mendasari tiap-tiap permintaan atau disiplin, tetapi juga menggunakan kekuasaan bila perlu, mengharapkan anak untuk mematuhi orang dewasa tetapi juga mengharapkan anak untuk mandiri dan mengarahkan diri sendiri, saling menghargai antara anak dan orang tua, memperkuat standar perilaku. Orang tua tidak mengambil posisi mutlak, tetapi juga tidak mendasarkan pada kebutuhan anak semata (Santrock, 2007).

Berdasarkan tabel 4.2 responden yang tidak pernah melakukan perilaku seksual sebanyak 96 responden $(85.7 \%)$. Menurut Sarwono (2011) perilaku seksual adalah segala tingkah laku manusia yang didorong oleh hasrat seksual, baik dengan lawan jenisnya maupun dengan sesama jenis.

\subsubsection{Analisa Bivariat}

Berdasarkan hasil penelitian yang telah dilakukan, didapatkan tidak ada hubungan hubungan pola asuh orangtua dengan perilaku seksual pada remaja di SMK Teknologi Migas Pekanbaru, dengan diperoleh nilai $\mathrm{p}=0,204>0,05$. Sejalan dengan penelitian yang dilakukan oleh Robii'atul Adawiyyah di SMA Islam Samarinda tahun 2016 bahwa penelitiannya juga menyatakan tidak ada hubungan antara pola asuh orangtua dengan perilaku seksual, dengan ( $\mathrm{p}$ value) sebesar 0,781 sehingga lebih besar dari nilai $(\alpha)=0,05$.

Dari hasil penelitian di atas, berbanding terbalik dengan hasil penelitian yang dilakukan oleh Elizabeth Estin (2009), bahwa dari analisis statistika diperoleh nilai signifikan ( $\mathrm{p}$ value) sebesar 0,000 sehingga lebih kecil dari nilai $(\alpha)=0,05$. Hal ini berarti Ho ditolak sehingga dapat disimpulkan terdapat hubungan yang bermakna antara pola asuh orang tua terhadap perilaku seksual remaja.

Pola asuh orangtua terhadap anak merupakan bentuk interaksi antar anak dan orangtua selama mengadakan kegiatan pengasuhan yang berarti orangtua mendidik, membimbing, dan mendisiplinkan serta melindungi anak untuk mencapai kedewasaan sesuai dengan norma-norma yang berlaku dalam lingkungan setempat dan masyarakat. Pola asuh yang ditanamkan 
tiap keluarga berbeda dengan keluarga lainnya. Hal ini tergantung dari pandangan pada diri tiap orangtua (Gunarsa, 2007).

Berdasarkan hasil penelitian di atas dapat ditarik kesimpulan bahwasanya perilaku seksual pada remaja tidak hanya di pengaruhi oleh pola asuh orangtua, tapi juga dipengaruhi oleh lingkungan dan teman sebaya, yang mana pada dasarnya remaja lebih mempercayai teman sebaya. Tempat penelitian yang dilakukan para remaja bersekolah di daerah yang masih kental dengan adat istiadat, yang dimana para pelajar masih banyak dididik dengan sistem demokrasi, agama yang kuat, sehingga membuat remaja masih bisa mengontrol perilaku seksualnya.

\section{KESIMPULAN}

Dari hasil penelitian yang telah dilakukan dapat disimpulkan antara lain :

1.Hasil dari penelitian terdapat 106 responden $(94.6 \%)$ pola asuh orangtua demokrasi, sebanyak 6 responden $(5.4 \%)$ pola asuh orangtua otoriter, sebanyak 0 responden $(0 \%)$ pola asuh orangtua permisif. Pada uji bivariat, peneliti membagi kelompok pola asuh hanya 2, yakni demokrasi dan otoriter, hal ini disebabkan nilai permisif nol, sehingga tidak diolah. Dari hasil penelitian menunjukkan rata-rata pola asuh orangtua adalah demokrasi.

2.Hasil penelitian menunjukkan responden yang pernah melakukan perilaku seksual 16 responden $(14.3 \%)$, sedangkan responden yang tidak pernah melakukan perilaku seksual 96 responden $(85.7 \%)$. Dari hasil penelitian menunjukkan rata-rata skor responden yang tidak pernah melakukan perilaku seksual.

3.Hasil penelitian menunjukkan didapatkan tidak ada hubungan hubungan pola asuh orangtua dengan perilaku seksual pada remaja di SMK Teknologi Migas Pekanbaru, dengan diperoleh nilai $\mathrm{p}=0,204>0,05$

\section{SARAN \\ Bagi pihak SMK Teknologi Migas Pekanbaru}

Sebagai bahan masukan dan pertimbangan bagi pengelola untuk dapat mengawasi perilaku siswa-siswi di SMK Teknologi Migas Pekanbaryu selama di sekolah. Dan juga dapat memberikan informasi tentang kesehatan reproduksi tepat kepada siswa-siswi yang berada di SMK Teknologi Migas Pekanbaru.

\section{Bagi Siswa/I di SMK Teknologi Migas Pekanbaru}

Agar siswa/i SMK Teknologi Migas Pekanbaru megetahui bagaimana pola asuh orang tua mereka dapatkan. Selain itu agar siswa/I SMK Teknolgi Migas Pekanabaru dapat mengendalikan perilaku seksual pada diri mereka.

\section{Bagi peneliti selanjutnya}

Diharapkan dapat melakukan penelitian lebih lanjut mengenai hubungan teman sebaya dengan perilaku seksual remaja, sehingga dapat diketahui sebesar apakan pengaruh teman sebaya terhadap perilaku seksual remaja.

\section{DAFTAR PUSTAKA}

Asparin, dkk. 2015. Analisis Faktor-Faktor Yang Berhubungan Dengan Perilaku Seksual Beresiko Pada Remaja SMA/Sederajat di Kecamatan Syngai Manau. 2014. Jurnal Universitas Jambi, 5566. Diakses tanggal 2 November 2017.

Adawiyyah, 2016. Hubungan Pola Asuh Orangtua Dengan Perilaku Seksual Pranikah Pada Remaja Di SMA Islam Samarinda.

Azmi, (2015). Hubungan Pola Asuh Orangtua dengan Perilaku Seksual Remaja di SMAN 1 Sanden Bantul. Diperoleh tanggal 13 November 2017. 
BKKBN.2009.Remaja dan SPN (Seks Pra Nikah).www.bkkbn.go.id. Webs Detail Rubrik.phpMyID=518.pdf. Diakses 10 November 2017

Chandra, Rahmawati \& Hardiani, (2014). Hubungan Tipe Kepribadian dengan Perilaku Seksual Beresiko Remaja di SMKN "X" Jember. Jurnal Pustaka Kesehatan, Vol.2 No 3. Diakses tanggal 2 November 2017.

Effendi, 2010. Perilaku Dorongan Seksual Pada Remaja. Makalah Seminar di Medan. USU Digital Library.

Gilang,D.(2015).62 Persen Remaja Sudah Tidak Perawan.Kompasiana.diakses dari http://www.kompasiana.com. Diakses pada tanggal 5 November 2017

Hidayati, A. 2013. Pengaruh Tingkat Pendidikan dan Pola Asuh Orang Tua terhadap Prestasi Pelajar. Jurnal Pendidikan, UNAND 13(3): 1-10

Jahja, Y. 2011. Psikologi perkembangan. Jakarta: Kencana prenada media group

Kasim. (2014). Dampak Perilaku Seks Beresiko Terhadap Kesehatan Reproduksi dan Upaya Penanganannya. Vol. 3, No 1. Diperoleh tanggal 10 November 2017.

Latifah. 2008. Karakteristik Remaja [online]. Tersedia:http://www.tumbuhkembanganak.blogspot.com/20008/05/karakteristikremaja.html.[1 November 2017]

Lisnawati. N. 2015. Faktor-Faktor yang Berhubungan dengan Perilaku Seksual Remaja di Cirebon. Skripsi
Luthviatin, Novia, DKK. 2012. Dasar-Dasar Promosi Kesehatan \& IlmuPerilaku. Jember: Jember University Press.

Mutiah, Diana, (2010). Psikologi Bermain Anak Usia Dini. Jakarta: Kencana.

Papalia, dkk., (2008). Human Development. Jakarta: Kencana Prenada Media Group

Santrock, J.W. (2007). Psikologi Perkembangan. Edisi 11 Jilid 1. Jakarta: Erlangga.

Sari, U.M. 2007. Perbedaan Perilaku Asertif Pada Remaja Ditinjau dari Pola Asuh Orangtua.

Sarwono SW. (2008). Psikologi Remaja. Jakarta : PT Grafindo Persada.

Skripsi. Fakultas Psikologi.Universitas Kristen Soegijapranata. Semarang. Diakses dari http;//eprints.unika.ac.id tanggal 12 November 2017.

Sofyan.(2013). Perilaku Remaja. Jakarta, Salemba Medika

Yuldawati. (2008). Hubungan antara Pola Asuh Orang Tua dan Perilaku Seksual Pelajar SMA Negeri di Kota Solok. Tesis Dipublikasikan. Jakarta: Magister Kesehatan Masyarakat Universitas Indonesia. 